\title{
Book of Abstracts
}

6th ISPAS International Workshop, 22-23 March 2016. International Society of Performance Analysis of Sport. Carlow, Ireland.

\section{Analytics in Sport}

\author{
PETER O'DONOGHUE \\ Cardiff School of Sport, Cardiff Metropolitan University, Cardiff, United Kingdom
}

\begin{tabular}{|c|c|c|}
\hline \multicolumn{3}{|c|}{ ABSTRACT } \\
\hline \multicolumn{3}{|c|}{$\begin{array}{l}\text { Data analytics is become increasingly used in high performance sport as sports governing bodies and elite } \\
\text { sports organisations exploit analytics techniques that have been used successfully in medicine, business, } \\
\text { criminology and other domains. However, the term "analytics" has also been misused in sports contexts to } \\
\text { describe rather routine data analysis processes. The purpose of the current presentation is to discuss the } \\
\text { distinction between data analysis and data analytics. Designing a European International soccer tournament } \\
\text { is used as an example of data analytics in sport. There are things that data analytics and more routine data } \\
\text { analysis have in common. These include the use of multiple data sources, multiple data types, abstraction } \\
\text { and a reductive approach to data processing. }\end{array}$} \\
\hline & & \\
\hline Data types and sources & Relatively Simple, Centralised & $\begin{array}{l}\text { Complex, } \\
\text { distributed }\end{array}$ \\
\hline Data quality & Complete, clean & $\begin{array}{l}\text { Incomplete, inconsistent, } \\
\text { updating (streaming) }\end{array}$ \\
\hline Data format & Consistent & Variable \\
\hline Analysis methods & Small number of methods & Large array of analysis tools \\
\hline $\begin{array}{l}\text { Decision makers' view of data } \\
\text { processing }\end{array}$ & Opaque & Transparent \\
\hline $\begin{array}{l}\text { Relation between analysis and } \\
\text { decision making tasks }\end{array}$ & $\begin{array}{l}\text { Separated and in sequential, } \\
\text { lapse time analysis }\end{array}$ & $\begin{array}{l}\text { Undertaken concurrently, real- } \\
\text { time analysis }\end{array}$ \\
\hline Output & Fixed report from an analysis & Interactive dynamic presentation \\
\hline Data querying & $\begin{array}{l}\text { Stable process with some ad hoc } \\
\text { querying }\end{array}$ & $\begin{array}{l}\text { Interactive visualization, } \\
\text { exploratory queries }\end{array}$ \\
\hline
\end{tabular}

Corresponding author. Cardiff School of Sport, Cardiff Metropolitan University, Cyncoed Campus, Cardiff, CF23 6XD, Wales, UK.

E-mail: podonoghue@uwic.ac.uk

6th ISPAS International Workshop, 22-23 March 2016. International Society of Performance Analysis of Sport. Carlow, Ireland. JOURNAL OF HUMAN SPORT \& EXERCISE ISSN 1988-5202

(c) Faculty of Education. University of Alicante

doi:10.14198/jhse.2017.12.Proc2.06

S530 | 2017| Proc2 | VOLUME 12

C 2017 University of Alicante 
The main differences between analytics and traditional data analysis are summarised in Table 1. Readers may recognize elements of analytics that are also common in some routine analyses and vice versa. Therefore, the distinction between traditional data analysis and data analytics is not clear cut. However, where a majority of the elements in the analytics column exist within a process, the term "analytics" is justified. Essentially, data analytics involves expert human analysis being fully integrated with computerized data analyses techniques within flexible real-time decision making processes. Consider a soccer governing body considering the design of a European International soccer tournament. Decisions need to be made about competition format and seeding. The governing body would be interested in forecasting the impact of different tournament structures on the chances of teams of different strengths reaching different stages, the chances of the host nation and the overall duration of the tournament. Models may provide conflicting predictions due to discrepancies between FIFA World rankings and European Ranking Coefficients. There is a great deal of subjective knowledge about soccer tournaments that experts can add to quantitative analyses within such decision making processes. Hence the analysis is done within expert meetings rather than being completed before hand. 


\title{
Performance analysis of football in the blogosphere: Measuring the high press
}

\author{
NIC JAMES ${ }^{1}$, GETHIN REES ${ }^{2}$, GORAN VUČKOVIĆ 3 \\ 1 University of Middlesex, United Kingdom. \\ 2Swansea FC, Wales, United Kingdom. \\ ${ }^{3}$ University of Ljubljana, Slovenia.
}

\begin{abstract}
Pressing is used to describe a team's efforts to win possession back from the opposition. When some members of the team (usually the attacking players) rush towards the ball carrier and other players to restrict the time available to play the ball, football pundits describe the behaviour as pressing or a high press (high pressure). This behaviour usually takes place in the opponent's half of the pitch and is associated with teams such as Barcelona. Hence it has been suggested that the high press is a desirable way to play football and is indicative of success (a performance indicator). In order to quantify this behaviour Trainor (2014) introduced the metric PPDA (Passes allowed Per Defensive Action). Defensive actions recorded were tackles (won), challenges (failed tackles), interceptions and fouls as these defensive actions can be recorded objectively e.g. these are included in Opta's data collection of action variables (Opta, 2012). Since each team in each match will have a different number of opportunities to undertake these defensive actions the total number of defensive actions is normalised with respect to the opposition's number of passes. Trainor also stressed the need to determine which area of the pitch to consider when measuring the intensity of pressing. He decided to use the opponent's entire half of the pitch plus a small section of the defending team's half on the basis that a team might be happy to concede possession in the opponent's half but could tenaciously apply pressure once the ball entered their own half. This may be true but using just the opponent's half of the pitch has the advantage of simplicity and repeatability.
\end{abstract}

All English Premier League matches from the 2013/14 and 2014/15 seasons were analysed using data collected by Opta. Individual teams were assessed for their ability to press the opposition and prevent the opposition from pressing them. PPDA was calculated as:

$\sum$ Successful + unsuccessful passes (played in a team's own half)

$$
\overline{\sum \text { Tackles won }+ \text { Tackles lost + Interceptions }+ \text { Fouls conceded (by opponents) }}
$$

This metric was assessed to determine whether it is a valid performance indicator. Results provided evidence to suggest the metric is a useful measure of how teams play but its utility as a performance indicator is limited. Future research should consider other factors which contribute to measuring the high press such as defensive clearances and player work rate data. 


\section{REFERENCES}

1. Opta. (2012). OptaPro and Manchester City launch MCFC analytics. Retrieved from: http://www.optasports.com/news-area/optapro-and-manchester-city-launch-mcfc-analytics.aspx

2. Trainor, C. (2013). Defensive metrics: An introduction. http://statsbomb.com/2013/10/defensivemetrics-an-introduction/

3. Trainor, C. (2014). Defensive metrics: Measuring the intensity of a high press. http://statsbomb.com/2014/07/defensive-metrics-measuring-the-intensity-of-a-high-press/ 


\title{
Performance analysis of football in the blogosphere: Goal scoring
}

\author{
GETHIN REES ${ }^{1}$, NIC JAMES ${ }^{2}$, GORAN VUČKOVIĆ ${ }^{3}$ \\ ${ }^{1}$ Swansea FC, Wales, United Kingdom. \\ 2 University of Middlesex, United Kingdom. \\ 3 University of Ljubljana, Slovenia.
}

\begin{abstract}
Quantitative methods to determine which performance indicators are key to success within football have largely centred on on-the-ball activity. Thus the majority of empirical research has been developed on goal data (e.g. Bate, 1988, Hughes and Franks, 2005), shot data (e.g. Lago-Ballesteros \& Lago, 2010), possession (e.g. Lago, 2009, Lago \& Delall, 2010) and passing (e.g. Szwarc, 2004, Oberstone, 2009) to discriminate top, middle and bottom teams. As scoring is the ultimate objective in football, and for this to occur a team has to attempt a shot, analysis of shooting tendencies has been used as a measure of a team's ability.

Recent work has attempted to use shots as a way of describing 'dominance' in individual matches. The premise being that if one team has increased their shot production, whilst limiting their opposition's attempts at goal, then this is a strong indicator of 'dominance' in that particular match, irrespective of other elements of play such a possession or passes. Total Shots Ratio (TSR) is one such metric which attempts to measure a team's dominance over their opposition in a given match simply by using shot data of both teams and creating a score based upon the following equation; TSR = Total shots for/(Total shots for + total shots against). The equation generates a team score of between 0.0 and 1.0 , with any team achieving a score over 0.5 being seen to have dominance over the opposition. Similarly, Shots on Target Ratio (SoTR) works in exactly the same way, but only using shots that were deemed to be on target. The rationale being that such shots are a better indicator of quality of chance created. Furthermore, Shot Dominance (ShotDom) explains dominance in a game by developing a ratio measure between the two competing teams in their shots created; that is if Team A has 10 shots and Team B has 5 shots, then Team A has a ShotDom score of 2.0, whilst Team $B$ has a score 0.5 . Such metrics are popular in on-line blogging communities, but as yet have received little academic investigation.

The following investigation will use Opta data from the 2014-15 English Premier League season, collected from the 442Statszone website in an attempt to (a) assess the frequency that the winning team exhibits a superior score in each of the shot metrics, TSR, SoTR and ShotDom (b) via developing team average scores for each of these statistics, correlate against final league standing and (c) compare these statistics against traditional statistics possession and pass completion rate. Results can potentially provide useful information regarding the robustness of such metrics, whilst providing important summary information regarding the effectiveness of a team's tactics in a particular match.
\end{abstract}




\section{REFERENCES}

1. Bate, R. (1988). Football chance: Tactics and strategy. In T. Reilly, A. Lees, K. Davids, \& W. Murphy (Eds.), Science and Football (pp. 293 - 301). London: E \& FN Spon.

2. Hughes, M., \& Franks, I. (2005). Analysis of passing sequences, shots and goals in soccer. Journal of Sports Sciences, 23(5), 509-514.

3. Lago, C. (2009). The influence of match location, quality of opposition, and match status on possession strategies in professional association football. Journal of Sports Sciences, 27, 14631469.

4. Lago, C., \& Dellal, A. (2010). Ball possession strategies in elite soccer according to the evolution of the match-score: the influence of situational variables. Journal of Human Kinetics, 25, 93-100.

5. Lago, C., Lago-Ballesteros, J., Dellal, A., \& Gómez, M. (2010). Game-related statistics that discriminated winning, drawing and losing teams from the Spanish soccer league. Journal Of Sports Science \& Medicine, 9(2), 288.

6. Oberstone, J. (2009). Differentiating the top English premier league football clubs from the rest of the pack: Identifying the keys to success. Journal of Quantitative Analysis in Sports, 5(3).

7. Szwarc, A. (2004). Effectiveness of Brazilian and German teams and the teams defeated by them during the 17th Fifa World Cup. Kinesiology, 36(1), 83-89. 


\title{
"Don’t forget your roots!"
}

\author{
STAFFORD MURRAY, CHRIS WHITE, JULIA WELLS \\ English Institute of Sport (EIS), United Kingdom.
}

\begin{abstract}
The EIS performance analysis team has grown in many directions, firstly we have listened to sports needs and deployed PA's across World, Olympic \& Paralympic sports in Great Britain and secondly the team has embraced change through the development of video and data driven processes to increase the probability of an athlete being successful. The aim of this presentation is to demonstrate how this has impacted sports programme delivery, the discipline itself and highlight the key future directions that drive us to be the world's leading PA team.

With UK Sport and Lottery funding we have a huge responsibility to deliver to the sports and impact on performance. Post 2012 the newly formed EIS Performance Solutions team was introduced to sports to support the defining of 'what it takes to win' (WITTW) models and aligning sport science \& medicine practitioners, technology and engineering to the sports performance plan. The WITTW models have opened the door even wider to performance analysis services as the PA team are in many ways the 'gate keeper' to the performance data. Working as a multi-disciplined team the PA's are contributing to decision-making by PD's and identifying future directions of programme support \& funding. This is an exciting place to be however this brings large responsibilities on our PA's shoulders, so what have we done about it?

Data integrity, understanding your data and its interpretation is key to the process. Would you trust in anyone else's data, let alone your own data? Using data in isolation is always a challenge as the context of how a performance was achieved is missing. Sports structures such as rules or regulations change from year to year, cycle to cycle and so it's important to capture and appreciate this in the interpretation of results and when this is combined with video evidence then we are only strengthening the interpretation of the data... so "don't forgot your roots!".
\end{abstract}




\title{
Player rating systems in the invasion-territorial sports: some insights from decision science
}

\author{
BILL GERRARD \\ Leeds University Business School, United Kingdom.
}

\begin{abstract}
Lewis (2003) highlighted the potential competitive gains in elite team sports from the application of data analytics to support player recruitment decisions. This study seeks to go beyond Moneyball by considering the issues involved in measuring player performance in the invasion-territorial team sports. The specific research objective is to investigate how performance (data) analysts can work effectively with coaches and scouts to construct player rating systems to be used to track own-player performances as well as to identify potential recruits.
\end{abstract}

A Decision-Theoretic Perspective on Player Rating Systems: From the decision-theoretic perspective Moneyball is a case study of the relative merits of using a systematic approach to evaluating alternative players using performance metrics rather than a non-systematic approach based on the subjective evaluations of scouts. A secondary aspect is the sabermetric issue of identifying the most predictive metrics (i.e. on-base percentage vs batting or slugging averages). But Moneyball represents a special case in which players are essentially being evaluated with regards to a single skill dimension (i.e. hitting or pitching). The more general case, to be found in the invasion-territorial sports such as the various codes of football, hockey and basketball, is evaluating players on multiple skill dimensions. There are two distinct problems, an identification problem of determining the most appropriate set of skill-specific performance metrics, and a composition (or weighting) problem of how best to combine the set of skill-specific performance metrics to construct a summary player performance rating. The decision-theoretic literature suggests that experts (i.e. coaches and scouts) are skilled in resolving the identification problem but algorithms provide a more effective solution to the composition problem (Dawes, 1988; Kahneman, 2012). And, following Dawes (1979) on the relative merits of proper and improper linear models, it is recognised that once units of measurement are standardised across different metrics (e.g. using Z scores), there may be little gain from applying multiple regression rather a simpler, non-sample-specific set of equal weights to combine the skill-specific performance metrics.

An empirical application: The differences between proper and improper linear models for rating players is investigated using data for 288 rugby league players with at least $25 \%$ game time during the 2013 Super League regular season in England. Eight performance metrics are available - games played, minutes played, carries, metres gained, tries scored, clean breaks, tackles made and missed tackles. All of these performance metrics are expressed as cumulative totals. In addition two further metrics are constructed - metres per carry, and tackle success rate. Players are ranked according to 16 different algorithms using Win Contribution (proper linear model with weightings derived from multiple regression analysis of team performance), Summed Z Scores (improper linear models with equal weights applied to Z-scores), and Time-Adjusted Ratings. The pairwise correlations between the alternative rankings are calculated. 


\section{RESULTS}

1. High correlation between Win Contribution and Summed Z Scores ( $r=0.812$ to 0.895$)$. Implication: improper linear ratings using standardised metrics provide a simple but good alternative to proper linear (i.e. regression-based) player rating systems.

2. Lower correlations between Summed Z Scores and Time-Adjusted Ratings ( $r=0.347$ to 0.674). Implication: treatment of game time has a significant effect on player ratings.

3. High correlation between Minutes Played plus Effectiveness and Win Contribution $(r=0.793)$. Implication: minutes played can act as a good proxy for activity levels but needs to be supplemented with effectiveness measures to provide an overall rating of performance.

The decision-theoretic perspective provides support for what could be called "coach-led analytics". Coachled analytics is an evidence-based approach in which coaching decisions set the agenda, with coaches and scouts providing expert guidance on the identification of key factors, and analysts constructing decision models that are jointly validated with coaches and scouts. The findings on so-called improper linear models suggest that accuracy in identifying key factors is much more important than the sophistication of the statistical techniques used to combine the factors into a decision calculus.

\section{REFERENCES}

1. Dawes, R. M. (1979), 'The robust beauty of improper linear models in decision making', American Psychologist, vol. 34, pp. 571- 582.

2. Dawes, R. M. (1988), Rational Choice in an Uncertain World, San Diego: Harcourt Brace Jovanovich.

3. Kahneman, D. (2012), Thinking, Fast and Slow, London: Penguin Books.

4. Lewis, M. (2003), Moneyball: The Art of Winning and Unfair Game, New York: Norton. 


\title{
Efficacy of half-back play in rugby and the impact of substitutions
}

\author{
G. SMYTH, M. HUGHES \\ Institute of Technology Carlow, Ireland.
}

\begin{abstract}
An exploratory method of quantifying the impact of individual players in rugby union was developed and applied to both half-back positions in 2015 Rugby World Cup matches, with a view to assessing the impact of their substitutions. It was hoped to extend this method to all positions. Instances where the starting halfback and the replacement played more than 20 minutes of the game were analysed. A match impact scoring system was devised using the questionnaire responses of an expert group of professional rugby analysts and experienced international coaches. The scoring system weighted each game action in a positive or negative manner according to the impact on team performance. The final match impact score for each player was divided by the number of seconds the team had in possession.
\end{abstract}

Sample data from the study would indicate that the starting scrum-half had a higher mean impact score than the replacement scrum-half $(9.64+/-3.94$ and $8.74+/-4.2$ respectively). The replacement out-half appeared to have a greater game impact than the starting out-half $(7.49+/-3.66$ and $5.11+/-4.30)$. An Intra-positional comparison of out-half and scrum-half positions showed that the out-half $(6.30+/-3.91)$ has lower mean game impact than scrum half $(9.18+/-4.38)$. The high standard deviation figures indicate that the impact of extraneous variables, such as evolving match score and weather conditions present many challenges to players.

The findings of this study would indicate that further research should examine the impact of substitutions in all positions in the team, with a view to forming a performance profile of replacement players and to quantify their contribution to match outcome.

Keywords: GAME IMPACT, SUBSTITUTIONS, RUGBY UNION.

\section{REFERENCES}

1. Hughes, M. T., Hughes, M. D., Williams, J., James, N., Vučković, G. and Locke, D. (2012). Performance indicators in rugby union. Journal of Human Sport and Exercise, 7:7, 383-401.

2. James, N., Mellalieu, S. and Jones, N. (2005). The development of position-specific performance indicators in professional rugby union. Journal of Sports Sciences, 23:1, 63-72.

3. Lim, E., Lay, B., Dawson, B., Wallman, K. and Aanderson, S. (2009). Development of a player impact ranking matrix in Super 14 rugby union. International Journal of Performance Analysis in Sport, 9:3, 354-367.

4. Villarejo, D., Palao, J., Ortega, E., Gomez-Ruano, M. and Kraak, W. (2015). Match-related statistics discriminating between playing positions during the men's 2011 Rugby World Cup. International Journal of Performance Analysis in Sport, 15:1, 97-111. 


\title{
Advanced methods of data analysis and their application to studying performance in team sports
}

\author{
GIANNI PISCHEDDA
}

23 The Gouldings, Uxbridge UB8 1LR, England, United Kingdom

\begin{abstract}
The interest in sports analytics for the past few years has put the focus on analysing data (as opposed to video) to monitor and improve performance. Thanks to the advances of technology, a lot of data on performance is being collected on the pitch (and training grounds). But in order to be useful this data need to be analysed effectively. The methods and tools for doing so have been available for many years (the methods long before computing power caught up with making their application possible). In fact they have been used profitably for years for analysing performance in business and other fields of human endeavour. The problem is that both methods and tools are often unknown or ignored by sports organisations who could greatly profit from their application.
\end{abstract}

This presentation aims to show how some of the most common methods used in business analytics can be usefully applied to the analysis of performance in team sports. It gives examples of each method and its application to a particular aspect of performance - of team and players. Each example is drawn from my experience in analysing performance in ice-hockey. And in particular of the Toronto Maple Leaves, a Canadian team which plays in the NHL - the most prestigious ice-hockey competition in the world. This takes place among teams US and Canada based teams.

The application of the following advanced methods to some common performance analysis problems will be shown:

1. Classification trees,

2. Ranking,

3. Hierarchical Clustering,

4. Association (link-play),

5. Visual analysis.

Corresponding author. 23 The Gouldings, Uxbridge UB8 1LR, England, United Kingdom

E-mail: gianni.pischedda@soccerlogic.com

Twitter: Johan @soccerlogic; Blog: soccerlogic.wordpress.com

6th ISPAS International Workshop, 22-23 March 2016. International Society of Performance Analysis of Sport. Carlow, Ireland. JOURNAL OF HUMAN SPORT \& EXERCISE ISSN 1988-5202

(c) Faculty of Education. University of Alicante

S540 | 2017| Proc2 | VOLUME 12

C 2017 University of Alicante 


\title{
Performance indicators that best predict points in professional rugby league
}

\author{
NIMAI PARMAR ${ }^{1}$, NIC JAMES ${ }^{1}$, ANDREW GREENHALGH ${ }^{1}$, MIKE HUGHES $^{2}$ \\ ${ }^{1}$ London Sport Institute, School of Science \& Technology, Middlesex University, London, United Kingdom. \\ 2Institute of Technology Carlow, Ireland.
}

\begin{abstract}
Past research has tried to predict future performances in soccer (Harrop and Nevill, 2014) and identified team performance indicators (PIs) in rugby union (Robertson, Back \& Bartlett, 2016). However, there are no similar approaches published for professional rugby league. Therefore this study will identify performance variables that best predict point's difference, which is suggested to give more meaningful information on match performance than match outcome alone, in professional rugby league matches and can therefore be deemed as Pls.

Opta rugby league data collected from all 27 rounds of the 2012, 2013 and 2014 Super League season amounting to 567 matches were extracted from Opta data sheets using visual basic programming and processed in Microsoft Excel (v2013, Microsoft Inc., Redmond, USA). A comprehensive list of action variables were used, these variables were made relative to each other i.e. home teams' carries subtracted by the away teams carries, this approach reduces the amount of variables included in the analysis. Action variables that related directly to points scored such as tries and conversions were removed where appropriate. Linear regression with Backwards stepwise method was used to analyse the data in IBM SPSS Statistics package (v21, IBM Corp., New York, USA).

Backwards-stepwise linear regression was used to assess the ability of action variables to predict the point's difference in professional rugby league matches. The final model had 15 action variables included with an $\mathrm{R} 2$ value of $.877(\mathrm{~F}(15,551)=261.93, \mathrm{p}<.001)$.

This study demonstrates a methodology that enables relevant and meaningful information to be produced that can be used by coaches and analysts. For example how performances on Pls can affect the final point's difference e.g. a one unit increase in relative total sets leads to 1.1 points added to the team's final score. Future research could build upon this research by analysing more matches, comparing Pls across different competitions and finally, develop positional Pls.
\end{abstract}

\section{REFERENCES}

1. Harrop, K. \& Nevill, A. (2014). Performance indicators that predict success in an English professional League One soccer team', International Journal of Performance Analysis in Sport, 14(3), pp. 907 920.

2. Robertson, S., Back, N. \& Bartlett, J. (2016). Explaining match outcome in elite Australian Rules football using team performance indicators, Journal of Sports Sciences, 34(7), pp. 637-644. 


\title{
A user centred design methodology for the development of technology in performance analysis of sport
}

\author{
ROBERT MOONEY1,2, LEO QUINLAN 3,4, GEARÓID ÓLAIGHIN1,2,4 \\ ${ }^{1}$ School of Engineering \& Informatics, NUI Galway, University Road, Galway, Ireland. \\ ${ }^{2}$ Bioelectronics Research Cluster, National Centre for Biomedical Engineering Science, NUI Galway, \\ University Road, Galway, Ireland. \\ ${ }^{3}$ School of Medicine, NUI Galway, University Road, Galway, Ireland. \\ ${ }^{4}$ CÚRAM (SFI Centre for Research in Medical Devices), NUI Galway, University Road, Galway, Ireland.
}

\begin{abstract}
There are a range of options available to sports scientists and coaches when choosing equipment for analysing athletic performance. However, dissatisfaction with a number of the most prominent systems currently available for the quantitative assessment of sports performance is limiting the extent to which quantitative analysis is taking place in applied settings (Mooney et al., 2015). The aim of this paper is to: (i) describe how a User Centred Design (UCD) methodology (Harte et al., 2014; Harte et al., 2015) can be used for development of novel systems for performance analysis in elite sport in order to address these issues and (ii) propose that this design approach may have application across a range of sports.
\end{abstract}

A Use Case was developed that details the concept for a new technology and describes how the intended end users (sports scientists, coaches and athletes) will interact with the technology during the various stages of its operation. A Use Case is an interactive system analysis tool which can be viewed by various stakeholders and is an effective way of gathering and defining user requirements and establishing the context of use. Interviews with potential end users were conducted $(\mathrm{N}=41)$. Feedback from each interview was used to revise and update the Use Case in order to improve end user agreement with various aspects of the system design.

Following multiple iterations of the Use Case, it was found that the final version received widespread acceptance from the study participants. $92.9 \%$ of total responses across all areas achieved positive feedback. Additionally, a score of $79.4 \pm 12.3$ was achieved for the System Usability Scale, which can be regarded as above average (McLellan, Muddimer, \& Peres, 2012).

UCD is a framework of iterative processes, which facilitates the design of a product, service or method in a powerful manner to ensure that the usability of the device is maximised and that it satisfies user requirements. It is recommended that future sports technology development follows this UCD methodology in order to maximise end user satisfaction and increase the likelihood of the adoption of new technology into existing practices of analysing sports performance in applied settings. 


\section{REFERENCES}

1. Harte, R., Glynn, L. G., Broderick, B. J., Rodriguez-Molinero, A., Baker, P., McGuiness, B., . . . ÓLaighin, G. (2014). Human centred design considerations for connected health devices for the older adult. Journal of personalized medicine, 4(2), 245-281.

2. Harte, R., Quinlan, L. R., Glynn, L., Rodriguez-Molinero, A., Scharf, T., Carenas, C., .. ÓLaighin, G. (2015). A Multi-Stage Human Factors and Comfort Assessment of Instrumented Insoles Designed for Use in a Connected Health Infrastructure. Journal of personalized medicine, 5(4), 487-508.

3. McLellan, S., Muddimer, A., \& Peres, S. C. (2012). The effect of experience on System Usability Scale ratings. Journal of Usability Studies, 7(2), 56-67.

4. Mooney, R., Corley, G., Godfrey, A., Osborough, C., Newell, J., Quinlan, L. R., \& ÓLaighin, G. (2015). Analysis of swimming performance: perceptions and practices of US-based swimming coaches. $J$ Sports Sci, 1-9. doi: 10.1080/02640414.2015.1085074 


\title{
Predicting the 2015 Rugby Union World Cup
}

\author{
SCOTT NICHOLLS ${ }^{1,2}$, NIC JAMES 1 \\ ${ }^{1}$ Middlesex University, London Sport Institute, London, United Kingdom. \\ ${ }^{2}$ English Institute of Sport, Manchester, United Kingdom.
}

\begin{abstract}
The accurate prediction/profiling (Reed \& O'Donoghue, 2005) of sporting performance can be considered an area of significant value and interest to coaches and sports teams at any level of competition. Historically, the prediction of sporting performance has usually been associated with the betting industry and gamblers alike (Hughes, 2015). However, all involved within sport will subconsciously process and evaluate various sources of information in an attempt to draw conclusions upon the outcome of future performance. Therefore, the aim of the study was to investigate whether an accurate predictive model utilising easily accessible pregame variables could be developed for international rugby union performance, specifically world cup competition.
\end{abstract}

A logistical regression model was created using the difference between 1) match score, 2) distance travelled from competitor's capital to that of the host nation and 3) official IRB ranking throughout the tournament from 48 matches at the 2011 RWC. All data was collated in relation to the superior ranked team. For example, within the NZL v AUS fixture, the values for each variable were, 1) 14 match points, 2) $-2322 \mathrm{~km}$ and 3) 3.41 ranking points. The model's B values were, Constant: -1.070862 , DistDiff: -0.000040 and RankDiff: 0.357434 . The model was applied to the 48 matches of 2015 RWC within two methods whereby predictive accuracy was assessed. Method 1 - Game-by-game prediction. Irrespective of the predictive accuracy, actual change in ranking was used for the following match. Method 2 - Pre-tournament prediction. The entire tournament was simulated using the predicted match outcomes and change in rankings using the IRB ranking methodology.

Method 1 was identified as the more accurate method, albeit still limited within its predictive accuracy. Method 1 correctly predicted $85 \%$ and $62.5 \%$ of group and knockout matches respectively ( $81.3 \%$ overall accuracy). The method identified $7 / 8$ quarter-finalists ( 4 in correct positions). Only $2 / 4$ quarterfinal results were predicted, however, both semi-final predictions were correct. Most notably, the final, and 3rd/4th placed playoff were incorrectly predicted. Although method 2 was not as accurate, the method did correctly predict $77.5 \%$ of group matches, in turn identifying $5 / 8$ quarter-finalists. However, only one of the final four was successfully identified (i.e. NZL).

Predicting the outcomes of elite rugby union matches simply using pre-game ranking and distance travelled can, in part, be used to predict match outcome. However, this appears only specific to the group stage, whereby team ability is more easily separated. As demonstrated, method 1 can predict the majority ( $85 \%)$ of group matches but unforeseen results always occur (e.g. JPNs win over RSA). Combined with expert input, the developed model could become a far more useful tool. The model herein appears a good starting point into predicting RWC results, however, future research should focus upon including additional pre-game 
variables (e.g. number of significant players missing, days rest, home advantage, referee decisions etc.) that would likely affect performance outcome and in turn, offer a greater predictive accuracy.

\section{REFERENCES}

1. Hughes, M. (2015). An overview of the development of notation analysis. In M. Hughes, \& I. M. Franks (Eds.), Essentials of performance analysis in sport (pp. 54-88). Oxon, United Kingdom: Routledge.

2. Reed, D., \& O'Donoghue, P. (2005). Development and application of computer-based prediction methods. International Journal of Performance Analysis in Sport, 5(3), 12-28. 


\title{
Using telecasting to identify turn times in alpine skiing
}

\author{
MIKAEL SWARÉN ${ }^{1}$, OSCAR LARSSON² ${ }^{2}$ GLENN BJÖRKLUND³ \\ ${ }^{1}$ Royal Institute of Technology, Mechanics Dept., Stockholm, Sweden. \\ 2Ultimate Performance $A B$, Uppsala, Sweden. \\ ${ }^{3}$ The Swedish Sports Confederation, Stockholm, Sweden.
}

\begin{abstract}
Alpine skiing can be considered as a "closed sport" where each athlete is alone in the course without any external disturbing moments. However, each alpine race is unique therefore never identical. In addition, the condition of the course is constantly changing as each skier makes new tracks in the snow. Identifying key performance indicators (KPI) and other characteristics are therefore difficult. The most frequently used analysis method in alpine skiing is video footage. However, it is not always possible for coaches to cover a complete course as they can be several kilometers long as e.g. downhill skiing. The purpose of this study was thus to explore the possibility to use telecasting to analyze performance and skiing characteristics in world cup slalom races to identify possible KPI.
\end{abstract}

Slalom races (men) from the 2014/2015 season were analyzed by two separate video analysts, at two different occasions. One analyst was a professional performance analysist in sports and the other analyst is a slalom ski coach. Standard telecasting footage from the races was for analyzing the turn times for the nine best racers. Typical error (TE) was calculated by;

$$
T E=\frac{\sigma_{\text {diff }}}{\sqrt{N_{\text {obs }}}}
$$

The standardized typical error (STE) was calculated by;

$$
S T E=\frac{T E}{\sqrt{\frac{\left(\left(n_{1}-1\right)^{2} \sigma_{1}^{2}+\left(n_{2}-1\right)^{2} \sigma_{2}^{2}\right)}{\left(n_{1}+n_{2}-2\right)}-T E^{2}}}
$$

The official race results were downloaded for all men world cup slalom races from the 2011/2012 season. Race times for the first and second runs were divided by the number of turns in each run.

TE between the two analysts was $0.03 \mathrm{~s}$ and STE was 0.14 . The fastest mean turn time was from the $2011 / 2012$ season, $0.819 \pm 0.027 \mathrm{~s}$ whereas the corresponding time for "slowest" season (2013/2014) was $0.849 \pm 027 \mathrm{~s}$.

There are clear differences in turn times between skiers, races and seasons. The STE was 0.13 which is below 0.2 and can hence be considered as trivial. The value of the TE $(0.03 \mathrm{~s})$ is most likely due to the framerate of the telecasting which is $25 \mathrm{fps}$. Each frame is hence $0.04 \mathrm{~s}$ and the analysts must choose one 
frame if the point of interest is between two frames. TE will presumably decrease with increase framerate. The combination of using official race results together with individual turn time analysis from telecasting footage provides a robust, cheap and effective method to objectively analyze skiing performance and identifying KPI. The results can also be used by coaches as an objective method to analyze skiing performance during training and also the quality of the training. 


\title{
Home advantage within the Six Nations (2000- 2015)
}

\author{
SCOTT NICHOLLS ${ }^{1,2}$, MATT MILLIGAN ${ }^{3}$, PAUL WORSFOLD 2,4 \\ ${ }^{1}$ Middlesex University, London Sport Institute, London, United Kingdom. \\ ${ }^{2}$ English Institute of Sport, Manchester, United Kingdom. \\ ${ }^{3}$ British Para-Swimming, Manchester, United Kingdom. \\ ${ }^{4}$ University of Chester, Chester, United Kingdom.
}

\begin{abstract}
It is a common belief that teams within sporting competition, involving both home and away fixtures will likely perform better within the home environment. This concept has been referred to as the 'home advantage' (HA) (Courneya \& Carron, 1992). Principally, HA stipulates that the number of wins and/or points accrued by a given team within home competition, will usually exceed that of corresponding away performances across the course of a competitive season. Indeed, within soccer, the strong prevalence of home nation victories across previous FIFA World Cup finals $(1930,1934,1966,1974,1978$ \&1998 (32\%)), in addition to the stark increase in British medals achieved during the London 2012 Olympics may serve to validate both the existence and influence of this phenomenon. However, aside from establishing the percentage points achieved at home by each team (Garcia, et al., 2012) and the rather crude statistics highlighting the commonality of hosting nations within Rugby World Cup Finals $(5 / 8 ; 63 \%)$, there would appear to be a lack of objective evidence regarding the level of HA within Six Nations competition. As such, the aim of the study was to twofold; investigate, 1) the existence of $\mathrm{HA}$ and 2) the level of 'home benefit' within Six Nations rugby (2000-2015).

A database of points scored (tries, penalties, conversions and drop goals) and competition standing points (Win - 2, Draw - 1, Lose - 0) achieved by each team competing within 240 Six Nations matches (2000-2015) was collated. Data was subsequently separated into home and away performance to establish associated differences. Data was analysed within two ways. Firstly, the points scored ('PS') by teams home vs. away were investigated to outline the 'home benefit', and thus outline whether teams were more successful (i.e. scoring more points or conceding less) within home performance. Secondly, the distribution (i.e. percentage) of league standing points gained (Points Achieved - 'PA') at home was investigated to establish whether teams win a greater proportion of league points at home, thus implying a HA.

Each team within the Six Nations, on average, performs better at home. Specifically, the home team scores more or concedes less than their respective away performance (table 1), thus demonstrating a positive "home benefit'. Overall, HA within the Six Nations tournament was worth 8.6 points (i.e. > 1 converted try). The consistently weaker teams based upon cumulative PA and championships won (Scotland and Italy) are the teams whom gain the majority of their standing points at home. Italy and Scotland gained $>75 \%$ in comparison to the 61, 58, 56 and $54 \%$ identified for England, France, Ireland and Wales respectively.
\end{abstract}


The PS by a team has a positive relationship with the HA, thus following the concept that teams perform better at home. However, the PA and thus, tournament standings has an inverse relationship with the HA. Generally for a team to top the standings overall, the team would be required to be consistent at gaining points both, home and away. Overall, HA appears to exist within Six Nations rugby, however, having the greatest HA (score line benefit or percentage of standing points achieved at home) does not guarantee tournament success. Other factors, such as the crowd and venue familiarity all contribute in some manner to how players perform, however, such factors and their effects are often not something that can be easily assessed, quantified and planned for. Future research should therefore incorporate technical performance variables to further shed light upon the phenomenon.

Table 1. Difference in home and away score line performance during the 2000-2015 Six Nations tournaments.

\begin{tabular}{cccc}
\hline Nations & Home & Away & Home Benefit \\
\hline England & 19.2 & 4.9 & 14.3 \\
Scotland & -6.9 & -11.7 & 4.8 \\
Ireland & 11.3 & 1.3 & 10.0 \\
Wales & 6.4 & -3.6 & 10.0 \\
France & 10.4 & 4.0 & 6.4 \\
Italy & -14.7 & -20.5 & 5.8 \\
\hline
\end{tabular}

\section{REFERENCES}

1. Courneya, K. S., \& Carron, A. V. (1992). The home advantage in sport competitions: A literature review. Journal of Sport and Exercise Psychology, 14, 13-27.

2. Garcia, M. S., Aguilar, O. G., Vazquez Lazo, J. C., Marques, P. S., \& Fernandez Romero, J. J. (2012). Home advantage in home nations, five nations and six nations rugby tournaments (1883-2011). International Journal of Performance Analysis in Sports, 13, 51-63. 


\title{
Risk factors for horse falls in the cross-country phase of national level British Eventing one day events
}

\author{
HEATHER CAMERON - WHYTOCK ${ }^{1}$, CHARLOTTE BRIGDEN ${ }^{1}$, ROBBIE WHYTOCK² \\ ${ }^{1}$ Myerscough College, St Michaels Road, Bilsborrow, Preston, PR3 ORY. United Kingdom. \\ 2University of Stirling, Stirling, Scotland, FK9 4LA, United Kingdom.
}

\begin{abstract}
Horse riding is a high risk sport. Numerous injuries and deaths to horses and riders occur in the cross country phase of eventing, with 45 rider deaths documented at national or international cross-country competitions between 2007 and 2013. Cross country requires the horse and rider to jump solid, immobile fences over undulating ground, in an optimum time. This test is preceded by a dressage and showjumping test during one day events.
\end{abstract}

Research suggests that the most important cause of horse and rider fatalities and injury on the cross country is the horse falling. Statistically, the highest risk of injury / fatality is associated with a rotational horse fall, in which the horse hits and somersaults over a solid obstacle, potentially landing on the rider.

The aim of the study was to investigate the risk factors associated with horse falls in the cross country phase of national level one day British Eventing competitions.

Data were recorded at 37 eventing locations between 2003 and 2012 for horse and rider partnerships ( $n=2002)$ at national British Eventing competitions. Factors recorded included horse factors (age, gender), event factors (location, month, year, level) and rider (gender, competitive position before cross country phase). Competition results data were analysed using generalised linear mixed effect models and AIC model selection.

Results suggest that rider position in the competition before cross country is the most important predictor of horse falls. Reasons for the observed relationship may include rider psychology and physiological capabilities of the horse and rider. If the riders were aware of their position before cross country then it is a possibility that competitive riding has a part to play in the risk of a horse fall. There is a need to further investigate the influence of rider psychology on horse falls during cross country competition. 


\title{
Tennis analysis and tournament design
}

\author{
ADAM SMITH, PETER O'DONOGHUE \\ Cardiff School of Sport, Cardiff Metropolitan University, Cyncoed Campus, Cardiff, CF23 6XD, Wales, United \\ Kingdom.
}

\begin{abstract}
The purpose of the current research is to discuss how performance analysis of tennis combined with computer simulation can provide information to assist those designing tennis tournaments. The current investigation considers reducing men's matches to the best of 3 sets and eliminating the second serve in both men's and women's singles would impact on tennis at Wimbledon.

Data for all completed matches of the 2014 Wimbledon men's and women's singles tournaments were collected from the official tournament website (www.wimbledon.org). This allowed the chance of winning points on first and second serve to be modelled in terms of player world rankings. A simulation system was developed to simulate 1000 singles tournaments using different modelling parameters. Six versions of the simulation system were run for the singles games shown in Table 1 and summary information about tournaments was output. The simulations assumed that if players only had one serve, then points would be played the same way current second service points are currently played.

Table 1 shows that only allowing one serve increases the number of service breaks and the percentage of matches where upsets occur while also reducing the length of matches, the number of tiebreaks required and the likelihood of higher ranked players progressing within tournaments. If men's singles matches were reduced to the best of 3 sets there would be more service breaks and upsets with higher ranked players finding it more difficult to progress to the latter stages of tournaments. This use of simulation evidenced by historical match data could provide an economic way for tennis tournament organisers to determine the impact of proposed rule changes without having to run experimental competitions.

Table 1. Simulation results for tournaments under different rules.

\begin{tabular}{|c|c|c|c|c|c|c|}
\hline \multirow[t]{3}{*}{ Variable } & \multirow{2}{*}{\multicolumn{2}{|c|}{$\begin{array}{c}\text { Women's Singles } \\
\text { Best of } 3 \text { sets }\end{array}$}} & \multicolumn{4}{|c|}{ Men's Singles } \\
\hline & & & \multicolumn{2}{|c|}{ Best of 3 sets } & \multicolumn{2}{|c|}{ Best of 5 sets } \\
\hline & 2 serves & 1 serve & 2 serves & 1 serve & 2 serves & 1 serve \\
\hline Sum of quarter-finalist World rankings & 100.4 & 427.3 & 173.9 & 399.2 & 134.0 & 396.0 \\
\hline$\%$ Tournaments won by $1^{\text {st }}$ or $2^{\text {nd }}$ seed & 62.4 & 33.7 & 48.7 & 25.5 & 59.0 & 36.2 \\
\hline \%Upsets & 30.2 & 50.4 & 35.1 & 48.2 & 31.7 & 48.7 \\
\hline \%Service breaks & 25.3 & 45.2 & 12.0 & 32.8 & 12.0 & 32.9 \\
\hline$\%$ Sets leading to tiebreaks & 8.8 & 5.1 & 17.9 & 7.0 & 31.5 & 12.7 \\
\hline Mean match time (mins) & 91.1 & 80.4 & 100.1 & 89.9 & 163.4 & 144.3 \\
\hline
\end{tabular}
\end{abstract}




\title{
Current physiological parameters of horse riders in equine specific education
}

\author{
C. JONES, E. BODEN
}

Myerscough College, St. Michaels Road, Billsborough, Preston, Lancashire, PR3 ORY., United Kingdom.

\begin{abstract}
In equestrian activities, the majority of riders will prioritise their horse's performance and fitness over their own, as they are under the impression that the horse is the only athlete in the partnership. Previous studies have discovered that amateur riders are physically weaker and have a poorer aerobic ability compared to that of other sports (Halliday, et al, 2011), and that an increased aerobic capacity helps to determine a rider's performance in competition (Devienne and Guezennec, 2000), therefore additional physical activity, and general fitness is essential. The aim of this study is to determine the current physiological parameters of female horse riders that are studying equine specific higher education courses.

In this longitudinal experimental study, female higher education students $(n=18)$, categorised by their year groups (year one, year two and year three), and staff $(n=6)$ participated in a maximal exertion programme to reach fatigue to allow for various physiological measurements adapted from Boden and Randle (2015) to be taken during the course of this physical activity. During the data collection period, each participant was required to wear a heart rate $(\mathrm{HR})$ monitor and express their feelings regarding tiredness on a fatigue visual numeric scale.

The multiple measurements taken include; basal fitness using a $20 \mathrm{~m}$ shuttle run (bleep test), sit and reach test and resting HR, blood lactate concentrations, body weight, body fat (four skin fold calliper method), height, reaction times and grip strength. Followed by a maximal graded exercise test on a treadmill with increasing speed and incline to induce fatigue, allowing for HR and velocity at which maximal oxygen uptake occurs (VO2max) to be measured with a Douglas Bag.

The results of the grouped data will be statistically analysed by using a two way analysis of variance (ANOVA) and furthermore, a one way ANOVA will be used to assess the fitness parameters of individuals in relation to the number of hours riding per week.

Pursuing the pilot study for this study it is evident that not all participants pushed themselves to maximum and that horse riders do not have a sufficient standard of physical fitness or a high level of physiological attributes to send achieve a greater amount in their sport.
\end{abstract}

Keywords: PHYSIOLOGY, RIDERS, EQUINE EDUCATON. 


\title{
Horse riding, exercise and fitness programmes: Are horse riders doing enough?
}

\author{
D. FLOOD, E. BODEN \\ Myerscough College, St Michaels Road, Bilsborrow, Preston, PR3 ORY., United Kingdom.
}

\begin{abstract}
Horse riding is a sport which requires skill, patience and strength, however, horse riding alone does not improve the fitness of the rider extra activities and exercise programmes should be used to improve the overall fitness of the rider. The aim of this part of the study was to gain information of the lifestyle, fitness and health choices of participants.

Participants $(n=23)$ were given a questionnaire as part of a wider study, to gain information on the lifestyle, fitness regime and thoughts on horse rider fitness in the industry. The information received from the questionnaire allowed the participants to be split into groups for the study.

All the answers to the questionnaire were collated and analysed in an excel spreadsheet. The results of the questionnaire showed that, $78.26 \%$ of the participants rated the importance of the horse riders fitness to be in the very important category, however only $50 \%$ of those who stated a high importance actually took part in a regular exercise programme and had a healthy diet. Of the whole participant group only $39.13 \%$ took part in a regular exercise programme when compared to the $60.87 \%$ who don't take part in a routine exercise programme.

The results of this study suggest that overall the participation of horse riders in regular exercise programmes off the horse are low, when compared to participation of the fitness training of other sports. An improvement in the participation of horse riders in fitness and exercise regimes could anecdotally reduce the risk of horse rider falls and injuries, and improve the overall sporting performance of the rider.
\end{abstract}




\title{
Do stride length and height indicate a racehorse's ability?
}

\author{
M. SULLIVAN, E. BODEN \\ Myerscough College, St Michaels Road, Bilsborrow, Preston, PR3 ORY., United Kingdom.
}

\begin{abstract}
The Thoroughbred Racing Industry is unique in its ability to attract a huge array of public attention from people in all different walks of life. The athletic prowess of the racehorses and the success that can be achieved is witnessed on a global scale. There are multiple factors which contribute to a successful racehorse, however it has been described that training is responsible for $70 \%$ of this success. The aim of this study is to determine whether stride length in training and height affect a racehorse's ability.

Stride Measurements (metres) will be collected through a piece of equipment called EquinlTy, which measures stride length through a GPS system when a light weight girth sleeve is applied to the horses tack. Stride length measurements will be taken between furlong 5 and 6 as the gallop isn't inclined on this part. A group of horses $(n=13)$ in training with Kübler Racing Ltd will take part in this study and stride length measurements will be taken from the Kingsdown and Long Gallops, Lambourn. Height measurements (centimetres) will be recorded using a measuring stick and time form ratings will be gathered from the Official Time Form Rating site. This research will benefit the industry as through performance analysis beneficial parameters will be highlighted to trainers and this can increase the chance of success.
\end{abstract}

An increase in knowledge of how stride length and height impact a horse's performance may help to improve success.

Keywords: STRIDE LENGTH, HEIGHT, ABILITY, TIME FORM RATINGS, SUCCESS. 


\title{
A ranking system for Gaelic football teams: factors that influence success
}

\author{
SHANE MANGAN ${ }^{1,2}$, KIERAN COLLINS $^{1,2}$ \\ ${ }^{1}$ Institute of Technology Tallaght, Ireland. \\ ${ }^{2}$ Gaelic Sports Research Centre, Ireland.
}

\begin{abstract}
The current investigation aimed to create an objective ranking of Gaelic football teams. The research examined various factors to assess their relationship to a team's ranking.

A modified version of the Elo Ratings formula (Elo, 1978) was used to create a ranking of Gaelic football teams. A total of 1101 competitive senior Inter County matches from 2010-2015 were incorporated into calculations. Factors that were examined between top and bottom rated teams included population, registration numbers, previous success at senior and underage levels, financial income from the GAA and number of clubs in a county.
\end{abstract}

At the end of the 2015 season, the highest rated team had 2194 Elo points, more than 3 times the amount of the lowest rated team (709 Elo points). The top 5 rated teams won significantly more $(p=0.01)$ senior All Ireland titles than lower rated teams in the last 15 years. The top 5 rated teams won significantly more minor provincial titles and All Ireland titles than lower rated teams in the last 15 years. The bottom 5 rated teams had a significantly lower $(p=0.04)$ ratio of Gaelic football teams to hurling teams in comparison to the top 5 rated teams. From 2011 to 2015 , the number of registered GAA players went up $20.51 \% \pm 13.86 \%$ on average. Although there was a non significant difference between top and bottom rated teams in terms of financial income from the GAA, the top rated team received more money per registered player for games development, than the rest of the top 10 teams combined (2010-2014).

Gaelic football teams can be objectively ranked using a modified Elo Ratings formula. In order to develop a successful senior team, counties should focus on the development of their underage players, particularly up to U18 level.

Keywords: GAELIC FOOTBALL, ELO RATING SYSTEM, RANKING TABLE, SENIOR SUCCESS, UNDERAGE SUCCESS

\section{REFERENCE}

1. Elo, A. E. (1978). The rating of chess players, past and present. Arco Publications. 


\title{
The statistical analysis of goalkeeper puck-outs during hurling matches
}

\author{
S. KELLY, P.J. BYRNE \\ Institute of Technology Carlow, Ireland.
}

\begin{abstract}
Hurling is one of Ireland's native Gaelic Games which is played between two teams of fifteen players on a grass rectangular pitch. The game is often referred to as one of the fastest field games in the world, however, published research into specific aspects of the game are still minimal. The aim of this investigation was to quantitatively analyse hurling goalkeeper puck-outs from senior Inter-County hurling matches during the 2014 All-Ireland league and championship season with a focus on which direction the sliotar (ball) followed when primary possession was not won.

Match $(n=18)$ recordings were taken from terrestrial television, digitised to DVD and then imported and analysed through SportsCode analysis software. 1031 puck-outs were observed with outcome measures documented respectively. To investigate the directional distribution from the puck-outs, four categories were created referring to each direction (Backwards, forwards, left and right).

Statistical analysis revealed that there was a significant difference $(p \leq 0.001)$ between the four directions the sliotar followed from puck-outs. Post-hoc tests revealed that the breaking-ball was redirected backward (21.5 \pm 3.87 puck-outs) significantly more than the other three directions, which comprised of forward (11.4 \pm 2.95 puck-outs), left ( $3.1 \pm 1.83$ puck-outs) and right ( $3.7 \pm 1.64$ puck-outs). $54 \%$ of all breaking ball puck-outs were redirected back towards the goalkeeper with $29 \%$ of puck-outs directed forward towards the opposition's goal. The sliotar was redirected left and right, $8 \%$ and $9 \%$ respectively from these puck-outs.
\end{abstract}

There are still many questions to be answered about hurling puck-outs, however, the significant differences revealed with respect to the four directions the sliotar followed from puck-outs support the implementation of offensive and defensive strategies by hurling team coaches. 


\title{
Engaging the players in the performance analysis process in a club hurling team
}

\author{
STEPHEN BEHAN, DENISE MCGRATH \\ MSc Coaching \& Exercise Science, University College Dublin, Ireland.
}

\begin{abstract}
A Performance Analysis (PA) program was introduced into a senior hurling team in Dublin. Existing literature defines the coach as the 'gatekeeper' of information in the practice of PA, with the athlete's performance being the subject of that information. Players are often not included in the process of PA itself, which could potentially have a negative impact on the motivation of the athlete.

A player-centered approach was adopted through out the process, with the hope of establishing an incremental change in the culture of the team. Team management and analyst defined operational definitions and potential performance indicators, from which the players chose focus points for each game. This being an amateur organisation did not allow for regular video sessions so video analysis was provided for each focus point and privately shared with the team through social media. Players led discussions then took place through the same platform. However, as the season progressed, player feedback waned.

A new format was introduced, and player engagement significantly increased. Individual player feedback systems were also introduced. Together, these resulted in training interventions and a successful finish to the season. This player-centered approach has started a reflective culture within the team, which can increase the player's intrinsic motivation. While there is a large amount of research into PA as a process, there is only a small amount of research focusing on the athletes at the centre of this process. Taking into account different pedagogical needs of players, along with the advancements in coaching science, it is warranted that the two strands should become more closely linked in the future.
\end{abstract}




\title{
A statistical analysis of Kilkenny Senior Hurlers during the 2015 season
}

\author{
LOUISE BYRNE, EMMA BYRNE \\ Institute of Technology Carlow, Ireland.
}

\begin{abstract}
Hurling is a multi directional and multi skilled field sport. It is native to Ireland and is labelled the world's fastest field sport. The levels of popularity and participation levels in hurling have increased but research in this area remains limited in comparison to other team sports. This case study gives an insight into Kilkenny's route to Leinster Championship and All Ireland Titles in 2015. The aim of this research was to assist management and players throughout the season and benchmark performance for specific KPI's.

Various KPI's were agreed between players and the management team and were the focus of all analysis from each game. In total 10 games $(n=10)$ were analysed which included 6 League matches, 2 Leinster Championship games and 2 All Ireland series games. These were analysed using video footage obtained by independent video footage and from broadcasters. These were imported into Sportscode video analysis software to be analysed post match.
\end{abstract}

KPI's analysed in all 10 games were Scores, Attempts, Puckouts, Frees, Blocks/hooks, Lost Possession and Breaking ball.

Key findings included Kilkenny scoring 16 goals whilst conceding 10 goals to their opponents. Total points scored 195 with Kilkenny conceding 187 . Kilkenny had $54 \%$ success rate from attempts whilst opponents had collectively higher at $64.5 \%$ successful scores from attempts.

Kilkenny are known for their high intensity and work rate which they bring to games particularly when turning over opposition which is evident in Blocks/hooks with 171(65\%) in comparison to opposition 92(35\%) over the seasons competitive games.

These KPl's were used to plan training sessions and formed the basis of the agenda at team meetings in preparation for upcoming games. Player's engagement in the process and their understanding of the whole process evolved since its introduction. Only the sums and means were tabulated from data obtained from analysis as no further statistical analysis were needed in this case. 


\title{
An analysis of shooting attempts in Inter County Gaelic football
}

\author{
SHANE MANGAN ${ }^{1,2}$, KIERAN COLLINS $^{1,2}$ \\ ${ }^{1}$ Institute of Technology Tallaght, Ireland. \\ ${ }^{2}$ Gaelic Sports Research Centre, Ireland.
}

\begin{abstract}
The aim of this research was to investigate differences in shot outcomes and the build up to shots in Inter County Gaelic football. The study investigated differences in shot outcome, shot location, origin of shots and length of attacks in the build up to shots.

A total of 10 competitive senior men's Inter County Gaelic football matches from the 2014 and 2015 seasons were analysed. Both teams in every game were included in the study. Analysis of each game was carried out using SportsCodeC software. A shot analysis template was designed and tested for intra-rater reliability. A series of Mann-Whitney $U$ tests were conducted to compare the recorded key performance indicators between winning versus losing teams, home versus away teams and key versus regular games. A one-way ANOVA was used to compare scoring efficiency between shot zones and to compare length of attacks.
\end{abstract}

A significant difference was evident between shot location and scoring efficiency at the corresponding shot location ( $p=0.02)$. The variation of attack times in the build up to shots was significantly different $(p=0.00)$, with $42.6 \% \pm 10.5 \%$ of shots coming after attacks lasting 10 to 20 seconds. A ratio of shots taken to shots conceded was found to be significantly higher $(p=0.01)$ for winning teams $(1.3 \pm 0.3)$ in comparison to losing teams $(0.8 \pm 0.2)$. The percentage of shots that originated from opposition kick outs were significantly different $(p=0.046)$ between winning teams $(15.4 \% \pm 4.2 \%)$ and losing teams $(10.4 \% \pm 4.1 \%)$. In key games (Finals \& Semi Finals), a significantly $(p \leq 0.001)$ higher percentage of shots originated from a team's own kickouts compared to regular games.

Shot location will influence the likelihood of a shot being scored. The location and importance of the game will influence how a team attacks and defends.

Keywords: GAELIC FOOTBALL, SHOT LOCATION, SCORING EFFICIENCY, SHOT RATIO, SHOT ORIGIN. 


\title{
Offloading in the 2015 Rugby World Cup
}

\author{
JOHN FARRELL \\ Institute of Technology Carlow, Ireland.
}

\begin{abstract}
The aim of this study is to assess offloads during the Rugby World Cup 2015. Hendricks et al. (2013) described the offload as where the player in possession of the ball is tackled by the opposition, in the contact the ball carrier tries to pass or hand the ball to their team. In rugby union an offload is used by attacking teams to keep possession, continuing the attack, and with the intention of breaking the defensive cover to score a try (Pulling and Stenning, 2015).

The 48 games were coded using Sportscode Pro, exported into excel and will be analysed through SPSS. An offload was coded into nine categories. Those categories are the area on the field (1), playing position and team (2), time the offload was performed (3), the number of tacklers (4), position of the tackle (5), offload outcome (6), offload type (7), outcome of the possession (8), and meters made (9).

Results will highlight the accuracy of teams offloading game and show the areas on the field that teams most offload in. The results will be analysed across Tier 1 and Tier 2 nations along with a comparison of Northern and Southern Hemisphere teams. Offloads will also be compared across successful and unsuccessful teams. Prim and van Rooyen (2013) highlighted that winning teams in rugby league were associated with being able to perform an offload successfully.

The results will aim to shed some light on teams offloading pattern and shed some light on their risk taking. Results from Pulling and Stenning (2015) found a difference of 7.5\% in tries scored from offloads when Northern and Southern Hemispheres were compared. However, there has been no published research on offloads from any of the previous Rugby World Cups.
\end{abstract}

\section{REFERENCES}

1. Hendricks, S., Roode, B., Mattews, B., and Lambert, M. (2013). Defensive Strategies in Rugby Union. Perceptual and Motor Skills, 117(1), 1-23.

2. Prim, S., and van Rooyen, M. (2013). Rugby. In: McGarry, T., O'Donoghue, P. and Sampaio, J. (Eds.) Routledge Handbook of Sports Performance Analysis (pp. 338-356). London : Routledge.

3. Pulling, C., and Stenning, M. (2015). Offloads in Rugby Union: Northern and Southern Hemisphere International Teams. International Journal of Performance Analysis in Sport. 15, 217-228.

4. Van Rooyen, M.K., Lambert, M.I., and Noakes, T.D. (2006). Movement time as a predictor of success in the 2003 Rugby World Cup Tournament. International Journal of Performance Analysis in Sport, $6(1), 30-39$. 


\title{
European Junior Championships as a pre- requisite for Olympic success in swimming
}

\author{
CIARÁN TONER ${ }^{1}$, ROBERT MOONEY ${ }^{2}$, ALAN SWANTON ${ }^{3}$ \\ ${ }^{1}$ Carlow Institute of Technology, Ireland. \\ 2NUI Galway, Ireland. \\ 3 Irish Institute of Sport, Ireland.
}

\begin{tabular}{|c|c|c|c|c|c|}
\hline \multicolumn{6}{|c|}{ ABSTRACT } \\
\hline \multirow{2}{*}{\multicolumn{6}{|c|}{$\begin{array}{l}\text { Current research has focused on athlete career trajectories and how this can be used a form of talent } \\
\text { identification. According to Abernethy 2008, countries are attempting to develop structures to identify } \\
\text { exceptionally gifted athletes as early as possible so they can focus available resources on promising } \\
\text { individuals and promote their development in a sport. Research on career trajectories in swimming carried } \\
\text { out by Allen et al., } 2014 \text {, highlighted that a pathway towards elite performance is a critical factor in talent } \\
\text { identification. This paper aims to establish: (i) the number of European Junior (EJ) athletes who progressed } \\
\text { to Olympics, (ii) is a EJ medallist more likely to compete/medal at the Olympics. } \\
\text { A user friendly database was created in MS Excel to analyse large amounts of data extracted from } \\
\text { Swimrankings.net. Data was gathered from Men's } 50 / 100 / 200 / 400 / 1500 \text { Freestyle events ranging from } 2001 \\
\text { to } 2012 \text {. }\end{array}$}} \\
\hline & & & & & \\
\hline Table 1. 0 & cycle tran & & & & \\
\hline $\begin{array}{c}\text { Olympic } \\
\text { Cycle }\end{array}$ & $\begin{array}{c}\text { EJ } \\
\text { Finalists }\end{array}$ & Olympians & $\begin{array}{c}\% \\
\text { Transition }\end{array}$ & $\begin{array}{l}\text { Olympic } \\
\text { Finalists }\end{array}$ & $\begin{array}{l}\text { Olympic } \\
\text { Medals }\end{array}$ \\
\hline Athens & 280 & 56 & $19.9 \%$ & 10 & 4 \\
\hline Beijing & 271 & 122 & $45 \%$ & 21 & 8 \\
\hline London & 308 & 124 & $40.2 \%$ & 27 & 4 \\
\hline Total & 818 & 207 & $25.3 \%$ & $\begin{array}{c}37 \\
\text { (athletes) }\end{array}$ & 16 \\
\hline
\end{tabular}


Table 2: Freestyle event transition.

\begin{tabular}{cccccc}
\hline Event & EJ & Olympians & $\begin{array}{c}\% \\
\text { Transition }\end{array}$ & $\begin{array}{c}\text { Olympic } \\
\text { Finalists }\end{array}$ & $\begin{array}{c}\text { Olympic } \\
\text { Medals }\end{array}$ \\
\hline $\begin{array}{c}50 m \\
\text { Freestyle }\end{array}$ & 81 & 24 & $29.6 \%$ & 3 & 3 \\
$\quad 100 m$ & 85 & 25 & $29.4 \%$ & 4 & 0 \\
$\begin{array}{c}\text { Freestyle } \\
200 m\end{array}$ & 88 & 33 & $37.5 \%$ & 4 & 1 \\
$\begin{array}{c}\text { Freestyle } \\
400 m\end{array}$ & 80 & 24 & $30 \%$ & 3 & 0 \\
$\begin{array}{c}\text { Freestyle } \\
1500 m\end{array}$ & 210 & 18 & $8.5 \%$ & 5 & 1 \\
Freestyle & & & & & \\
\hline
\end{tabular}

Results highlight that $25 \%$ of European Junior finalists transition to the Olympics, with $45 \%$ of medallists making this transition. $5 \%$ of athletes who finaled at EJ went on to medal at the Olympics. One Some key findings from this study so far: ten athletes who have medalled at Olympics in the chosen events nine also medalled at EJ. Eight of these athletes medalled in the same event at the Olympics as they did at EJ. A further analysis of male and female events in is on-going at present.

\section{REFERENCES}

1. Abernethy, B. (2008). Introduction: Developing expertise in sport - how research can inform practice. In V (Eds.), Developing sport expertise (pp. 1-14). Abingdon: Routledge.

2. De Bosscher, V., De Knop, P., Van Bottenburg, M. and Shibli, S. (2006). A conceptual framework for Analysing sports policy factors leading to international sporting success, European Sport Management Quarterly, 6(2), pp. 185-215. 


\title{
The effect of partial sleep deprivation on agility and vertical jump in basketball players
}

\author{
KAMRAN HOSSEINZADEH GHASEMABAD, TENGKU FADILAH TENGKU-KAMALDEN \\ Department of Sport Studies, Faculty of Educational Studies, Universiti Putra Malaysia, 43400 Serdang, \\ Selangor Malaysia.
}

\begin{abstract}
The aim of this study was to examine the effects of partial sleep deprivation on two consecutive nights on agility and vertical jump of basketball players. Participants of this study were 30 healthy Iranian basketball players (male, Mage $=18.8$ years $(S D= \pm 1)$,) who had at least 5 years' experience in the secondary league of Iran, they were randomly assigned in partial sleep deprivation (PSD) $(n=15)$ and control group $(n=15)$. A pretest-posttest design was used in the present study. Two post-test was conducted after the first and second night of sleep deprivation. All the tests has been measured and recorded, and data were analyzed by SPSS version 22.

Result of repeated measure ANOVA illustrate that, a significant difference between the scores of treatment group in the three times of measurements, while the results of control group were not significant between the pre-test, post-test 1 and post-test 2. Subjects in PSD groups had a significant changes $(P<.05)$ in the first night of sleep deprivation and even more significant decrease $(P<.05)$ in the second night of sleep deprivation, however, control group has no significant differences $(P>.05)$ in their performance in all the measurement.

In conclusion partial sleep deprivation has significant effects on agility and vertical jump of basketball player and this effects is more outstanding when it goes for two consecutive nights.
\end{abstract}




\title{
Does the application of pilates into karate training enhance isometric and dynamic core strength of junior karate kumite players?
}

\author{
SEYEDEH NAHAL SADIRI, TENGKU FADILAH TENGKU-KAMALDEN \\ Department of Sport Studies, Faculty of Educational Studies, Universiti Putra Malaysia, 43400 Serdang, \\ Selangor Malaysia.
}

\begin{abstract}
Karate kumite involves repetitive one-sided moves such as punches, kicks and blocks, which in all of them if the core muscles are not strong enough to do their job accurately and perform the movements correctly, over time these incorrect movements can be stored and repeated which, may lead to injuries (Akuthota et al. 2008; Mętel, Milert, and Szczygieł 2012; Slobounov 2008). Research showed that Pilates is an efficient core training method in enhancing core strength (Critchley et al. 2011; Sekendiz et al. 2007; Wang et al. 2012); however, limited study has been carried to investigate the effects of Pilates in improving core strength of adolescent karate kumite players. Therefore, this study attempted to determine if the combination of Pilates and karate training improves isometric and dynamic core strength of junior karate kumite players.

The design of the study was a pretest-posttest randomised groups and the study lasted for 12 weeks. 29 male karate kumite players (junior category) from Hayashi-ha Karate Team, Kuala Lumpur randomly assigned into experimental $(n=15)$ and control $(n=14)$ groups. The experimental group completed 36 sessions of karate training including 30 minute Pilates (120 minutes, 3 times per week), while the control group only attended their regular karate training for 36 sessions ( 120 minutes, 3 times a week). Both groups were given tested regarding their isometric and dynamic core strength using Isometric Back Strength and Timed Sit-up test, respectively.

The data were analysed using paired sample and independent samples t-test. There was a significant difference between the mean of the experimental and control group in the level of isometric core strength $(\mathrm{t}$ $=2.13, p<0.05)$ and dynamic core strength $(t=2.66, p<0.05)$ after the intervention. Findings confirm that the application of Pilates into karate training leads to enhancement in junior karate players' isometric and dynamic core strength.
\end{abstract}

Keywords: KARATE, PILATES, CORE STRENGTH. 